
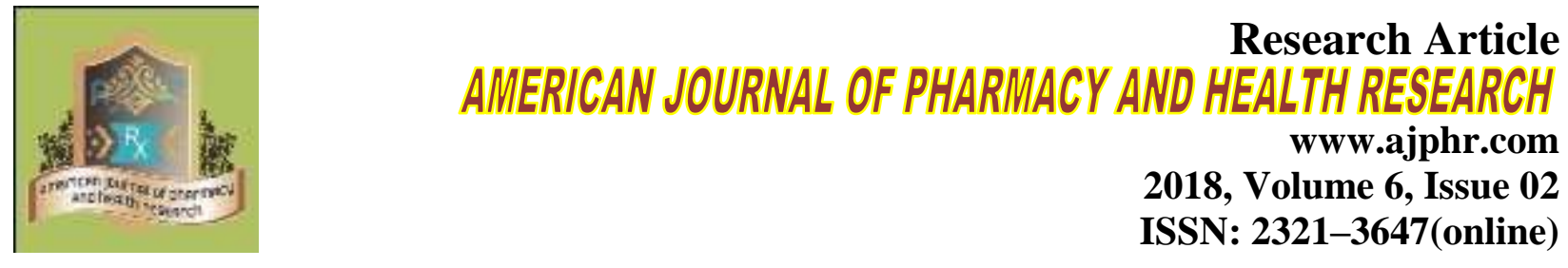

\title{
Inhibition of Formation of Fructose Induced Advanced Glycation End Products by Momordica chochinchinensis
}

\author{
Swathi Putta*, Eswar Kumar Kilari \\ Pharmacology Division, A.U. College of Pharmaceutical Sciences, Andhra University, \\ Visakhapatnam.
}

\section{ABSTRACT}

The present study evaluates the antioxidant potential of hydro alcoholic pericarp extract of Momordica chochinchinensis (HAPMC) using different model systems. To establish the link between glycation and oxidation processes, the HAPMC extract has been evaluated for its in vitro radical scavenging activity against superoxide, hydroxyl, hydrogen peroxide, nitric oxide, ferric and $\mathrm{ABTS}^{+}$radical and antiglycation activities like the inhibitory activities on bovine serum albumin (BSA) and as well as protein oxidation markers including protein carbonyl formation (PCO). The results indicated that the HAPMC possesses the highest antioxidant potential against superoxide, hydroxyl, hydrogen peroxide, nitric oxide, ferric radical and ABTS ${ }^{+}$ radical. The HAPMC extract at different concentrations (10-250 $\mu \mathrm{g} / \mathrm{ml})$ has significantly quenched the fluorescence intensity of glycated BSA and the glycoxidation measured in terms of advanced glycation end products (AGEs). Furthermore, the study demonstrated that the inhibitory effect of $H A P M C$ extract in preventing oxidative protein damages including effect on PCO formation, which are believed to form under the glycoxidation processes. These results clearly demonstrate that the HAPMC, owning to its antioxidant content, is capable of suppressing the oxidative stress, carbonyl stress and formation of AGEs and protein oxidation in vitro.

Keywords: Advanced glycated end products, Oxidation, Momordica chochinchinensis 


\section{INTRODUCTION}

Diabetes mellitus is an endocrine disorder characterized by chronic hyperglycemia, which results from an absolute or relative deficiency of or resistance to insulin. According to the World Health Organization (WHO), 346 million people suffer from diabetes worldwide, whereas deaths due to this disease will double between 2005 and 2030. The increased morbidity and mortality in diabetics is mainly due to poor glycemic control over a long period of time ${ }^{[1]}$.

Glycation is the non-enzymatic reaction between a protein and a reducing sugar, such as glucose and fructose ${ }^{[2]}$ resulting in the formation of a reversible structure called a Schiff 's base and undergoes rearrangements to the Amadori products that induce further oxidation, generating dicarbonyl compounds and finally advanced glycation end products. Glycation stress is one of the risk factors for aging from inside and outside of the body ${ }^{[3]}$. Evidence has shown that AGEs participate directly in the pathogenesis of diabetic complications by accumulation and cross linking of long lived proteins. ${ }^{[4,5]}$

Aminoguanidine is an established antiglycation agent shown to have serious side effects such as flu-like symptoms, gastrointestinal problems, and anemia ${ }^{[6]}$. In recent times researchers have been directed towards plant based medicine for the treatment of glycation and hyperglycemic conditions. Some herbal drugs like Allium cepa ${ }^{[7]}$; Garcinia indica ${ }^{[8]}$; Salvia reuterana ${ }^{[9]}$; Camellia sinensis ${ }^{[10]}$; Astragalus radix ${ }^{[11,12]}$; Teucrium polium ${ }^{[13]}$; Feronia limonia ${ }^{[14]}$ were reported to have antiglycation activity due to the presence of antioxidant principles. The quercitin, apigenin, kaempiferol; carotenoids like $\alpha, \beta$ - carotene,zeaxanin, lycopene, lutein and phenolic compounds like gallic acid, vanillic acid, ferulic acid, caffeic acid, proto catechuic acid were present in Gac (Momordica chochinchinensis) are reported to have biological activities like Immunomodulatory ${ }^{[15]}$, antiinflammatory, antimicrobial ${ }^{[16]}$, antioxidant ${ }^{[17]}$, DNA protective ${ }^{[18]}$, tumor growth and angiogenesis ${ }^{[19]}$ activities. Hence the present study was focused on the effect of hydroalcoholic pericarp extract of Momordica chochinchinensis against oxidative stress, carbonyl stress and fructose induced advanced glycation end products.

\section{MATERIALS AND METHOD}

\section{Materials:}

Nitroblue tetrazolium (NBT), bovine serum albumin (BSA) were obtained from Merck. 1,1diphenyl-2-picrylhydrazyl (DPPH), 2,4 dinitrophenylhydrazine (DNPH), trichloroacetic acid (TCA) were obtained from Sigma (St. Louis, MO, USA). 2.4.6-Tri- (2'-pyridyl)-1, 3, 5-triazine (TPTZ), 2, 2'- Azinobis- (3-ethylbenzothiazoline- 6-sulfonic acid) (ABTS) and Trolox were 
obtained from Sigma Aldrich Chemical Co., Ltd. (England). All other reagents were of analytical reagent $(A R)$ grade.

\section{Plant materials and preparation:}

The hydroalcoholic pericarp extract of Momordica cochinchinensis was obtained from Laila Implex, Vijayawada.

\section{Super oxide radical scavenging activity:}

The assay was based on the capacity of the aqueous extract to inhibit formazan formation by scavenging the superoxide radicals generated in a riboflavin-light- NBT system ${ }^{[20]}$. The reaction

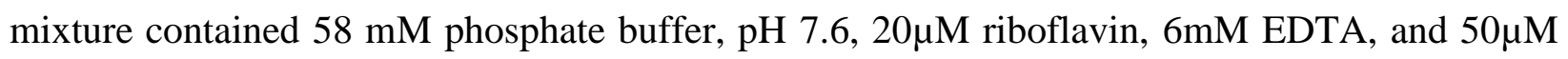
NBT, final volume made up to $3 \mathrm{ml}$, added in that sequence. Reaction was started by illuminating 40 volts under fluorescent lamp, the reaction mixture with different concentrations of HAPMC for 15 minutes. Immediately after illumination, the absorbance was measured at 560 $\mathrm{nm}$. The entire reaction assembly was enclosed in a box lined with aluminium foil. Identical tubes, with reaction mixture, were kept in the dark and served as blanks. The percentage inhibition of superoxide anion generation was calculated using the following formula:

$$
\% \text { Inhibition }=\mathrm{A}_{\mathrm{O}}-\mathrm{A}_{1 /} \mathrm{A}_{\mathrm{O}} \mathrm{X} 100
$$

Where A0 was the absorbance of the control, and A1 was the absorbance of the aqueous extract/standard.

\section{Hydroxyl radical scavenging activity:}

Scavenging activity of hydroxyl radical was measured by the method of Halliwell et al., 1985 ${ }^{[21]}$. Hydroxyl radicals were generated by a Fenton reaction $\left(\mathrm{Fe} 3^{+}\right.$-ascorbate-EDTA- $\mathrm{H}_{2} \mathrm{O}_{2}$ system), and the scavenging capacity of the extract and standard towards the hydroxyl radicals was measured by using deoxyribose degradation method. The reaction mixture contained 2deoxy-2-ribose (2.8 mM), phosphate buffer (0.1 mM, pH 7.4), ferric chloride $(20 \mu \mathrm{M})$, EDTA $(100 \mu \mathrm{M})$, hydrogen peroxide $(500 \mu \mathrm{M})$, ascorbic acid $(100 \mu \mathrm{M})$ and various concentrations of the test sample in a final volume of $1 \mathrm{ml}$. The mixture was incubated for $1 \mathrm{~h}$ at $37^{\circ} \mathrm{C}$. After the incubation an aliquot of the reaction mixture $(0.8 \mathrm{ml})$ was added to $2.8 \%$ TCA solution $(1.5 \mathrm{ml})$, followed by TBA solution ( $1 \%$ in $50 \mathrm{mM}$ sodium hydroxide, $1 \mathrm{ml}$ ) and sodium dodecyl sulphate $(0.2 \mathrm{ml})$. The mixture was then heated $\left(20 \mathrm{~min}\right.$ at $\left.90^{\circ} \mathrm{C}\right)$ to develop the colour. After cooling, the absorbance was measured at $532 \mathrm{~nm}$ against an appropriate blank solution. All experiments were performed in triplicates. The percentage of inhibition was expressed, according to the following equation: 


\section{$\%$ Inhibition $=\mathrm{A}_{\mathrm{O}}-\mathrm{A}_{1} / \mathrm{A}_{\mathrm{O}} \mathrm{X} 100$}

Where $A_{0}$ was the absorbance of the control without a sample, $A_{1}$ is the absorbance in the presence of the sample.

\section{Hydrogen peroxide radical scavenging activity:}

The hydrogen peroxide scavenging assay was carried out following the procedure of Ruch et al., $1989^{[22]}$. The principle of this method is that there is a decrease in absorbance of $\mathrm{H}_{2} \mathrm{O}_{2}$ upon oxidation of $\mathrm{H}_{2} \mathrm{O}_{2}$. A solution of $43 \mathrm{mM} \mathrm{H}_{2} \mathrm{O}_{2}$ was prepared in 0.1Mphosphate buffer ( $\mathrm{pH}$ 7.4). HAPMC at concentration in $3.4 \mathrm{~mL}$ phosphate buffer was added to $0.6 \mathrm{~mL}$ of $\mathrm{H}_{2} \mathrm{O}_{2}$ solution $(43 \mathrm{mM})$ and absorbance of the reaction mixture was recorded at $230 \mathrm{~nm}$. A blank solution contained the sodium phosphate buffer without $\mathrm{H}_{2} \mathrm{O}_{2}$.

\section{DPPH radical scavenging activity:}

The potential AA of extracts, fractions and pure compounds was determined on the basis of the scavenging activity of the stable 1,1 -diphenyl-2-picrylhydrazyl (DPPH) free radical. Aliquots of $1 \mathrm{ml}$ of a methanolic solution containing each pure compound were added to $3 \mathrm{ml}$ of $0.004 \%$ $\mathrm{MeOH}$ solution of DPPH. Absorbance at $517 \mathrm{~nm}$, against a blank of methanol without DPPH, was determined after $30 \mathrm{~min}$ (UV, Perkin-Elmer-Lambda 11 spectrophotometer) and the percent inhibition activity was calculated ${ }^{[23]}$. IC50 values denote the concentration of sample required to scavenge 50\% DPPH free radicals. All tests were run in triplicate and averaged.

\section{Nitric oxide radical scavenging activity:}

Nitric oxide generated from sodium nitroprusside in aqueous solution at physiological $\mathrm{pH}$ interacts with oxygen to produce nitrite ions, which were measured by the Griess reaction ${ }^{\text {[24] }}$. The reaction mixture $(3 \mathrm{ml})$ containing sodium nitroprusside $(10 \mathrm{mM})$ in phosphate buffered saline (PBS) and IBPG and the reference compound in different concentrations $(20,40,60,80$ and $100 \mu \mathrm{g}$ ) were incubated at $25^{\circ} \mathrm{C}$ for $150 \mathrm{~min}$. After incubation $1.5 \mathrm{ml}$ of the Griess reagent ( $1 \%$ sulphanilamide, $0.1 \%$ naphthyl ethylene diamine dihydrochloride in 2\% H3PO4) was added. The absorbance of the chromophore formed was measured at $546 \mathrm{~nm}$. The percentage inhibition of nitric oxide generated was measured by comparing the absorbance values of control and test samples.

\section{Reducing power:}

The reducing power of the extract was determined according to the method of Oyaizu $1986^{\text {[25] }}$. Various concentrations of the extracts $(\mathrm{mg} / \mathrm{ml})$ in distilled water were mixed with phosphate buffer $(2.5 \mathrm{ml}, 0.2 \mathrm{M}, \mathrm{pH} 6.6)$ and $1 \%$ of potassium ferricyanide water solution (2.5 ml, $\mathrm{K} 3[\mathrm{Fe}(\mathrm{CN}) 6])$. The mixture was incubated at $508 \mathrm{C}$ for $20 \mathrm{~min}$. Aliquots of trichloracetic acid 
( $2.5 \mathrm{ml}, 10 \%$ aqueous solution) were added to the mixture which was then centrifuged at 3000 rpm for $10 \mathrm{~min}$. The supernatant $(2.5 \mathrm{ml})$ was mixed with distilled water $(2.5 \mathrm{ml})$ and a freshly prepared $\mathrm{FeCl} 3$ solution $(0.5 \mathrm{ml}, 0.1 \%)$. The absorbance was measured at $700 \mathrm{~nm}$. Ascorbic acid was used as a positive control. In this method, the higher the absorbance, the higher the reducing power.

\section{Phosphomolybdinum method:}

The antioxidant activity of HAPMC extract was evaluated by the phosphomolybdenum method of Prieto et al., $1999^{[26]}$. An aliquot of $0.1 \mathrm{ml}$ of sample solution (equivalent to $100 \mathrm{lg}$ ) was combined with $1 \mathrm{ml}$ of reagent solution $(0.6 \mathrm{M}$ sulfuric acid, $28 \mathrm{mM}$ sodium phosphate, and 4 $\mathrm{mM}$ ammonium molybdate). In the case of the blank, $0.1 \mathrm{ml}$ of methanol was used in place of sample. The tubes were capped and incubated in water bath at $95{ }^{0} \mathrm{C}$ for $90 \mathrm{~min}$. After the samples were cooled to RT, the absorbance of the aqueous solution of each was measured at 695 $\mathrm{nm}$.

$\mathrm{Fe}^{+2}$ Chelating activity:

The chelating activity of the extracts for ferrous ions $\mathrm{Fe}^{2+}$ was measured according to the method of Dinis et al., $1994^{[27]}$. To $0.5 \mathrm{ml}$ of extract, $1.6 \mathrm{ml}$ of deionized water and $0.05 \mathrm{ml}$ of $\mathrm{FeCl} 2$ (2 $\mathrm{mM})$ was added. After $30 \mathrm{sec}, 0.1 \mathrm{ml}$ ferrozine $(5 \mathrm{mM})$ was added. Ferrozine reacted with the divalent iron to form stable magenta complex species that were very soluble in water. After 10 min at room temperature, the absorbance of the $\mathrm{Fe}^{2+}$ Ferrozine complex was measured at $562 \mathrm{~nm}$. The chelating activity of the extract for $\mathrm{Fe}^{2+}$ was calculated as Chelating rate $=(\mathrm{A} 0$ A1)/A0 $\times 100$, where A0 was the absorbance of the control (blank, without extract) and A1 was the absorbance in the presence of the extract.

\section{Ferric reducing ability power:}

The FRAP method measures the absorption change that appears when the TPTZ (2,4,6 -tri pyridyl-s-triazine)-Fe $\mathrm{Fe}^{3+}$ complex is reduced to the TPTZ-Fe ${ }^{2+}$ form in the presence of antioxidants ${ }^{[28]}$. An intense blue colour, with absorption maximum at $595 \mathrm{~nm}$, develops Briefly, the FRAP reagent contained $2.5 \mathrm{ml}$ of $10 \mathrm{mM}$ tripyridyltriazine (TPTZ) solution in $40 \mathrm{mM} \mathrm{HCl}$ plus $2.5 \mathrm{ml}$ of $20 \mathrm{mM} \mathrm{FeCl} 3$ and $25 \mathrm{ml}$ of $0.3 \mathrm{M}$ acetate buffer, $\mathrm{pH} 3.6$, was freshly prepared. The extracts were dissolved in ethanol at a concentration of $1 \mathrm{mg} / \mathrm{ml}$. An aliquot of $0.2 \mathrm{ml}$ of solution was mixed with $1.8 \mathrm{ml}$ of FRAP reagent and the absorption of the reaction mixture was measured at $595 \mathrm{~nm}$. Ethanolic solutions of known Fe (II) concentration, in the range of 50-1000 $\mu \mathrm{M}$ (FeSO4), were used for obtaining the calibration curve. The FRAP value represents the ratio 
between the slope of the linear plot for reducing $\mathrm{Fe}^{3+}-\mathrm{TPTZ}$ reagent by plant extract compared to the slope of the plot for $\mathrm{FeSO}_{4}$.

\section{ABTS $^{+}$Assay:}

ABTS assay was based on the method of Re et al., $1996^{[29]}$ with slight modifications. ABTS radical cation $\left(\mathrm{ABTS}^{+}\right.$) was produced by reacting $7 \mathrm{mM}$ ABTS solution with $2.45 \mathrm{mM}$ potassium persulphate and allowing the mixture to stand in the dark at room temperature for 12-16 h before use. The ABTS+ solution was diluted with ethanol to an absorbance of $0.70 \pm 0.02$ at $734 \mathrm{~nm}$. After addition of $25 \mu \mathrm{l}$ of sample or Trolox standard to $2 \mathrm{ml}$ of diluted $\mathrm{ABTS}^{+}$solution, absorbance at $734 \mathrm{~nm}$ was measured at exactly $6 \mathrm{~min}$. The decrease in absorption at $734 \mathrm{~nm}$ was used for calculating TEAC values. A standard curve was prepared by measuring the reduction in absorbance of ABTSo+ solution at different concentrations of Trolox. Appropriate blank measurements were carried out and the values recorded. Results were expressed as Trolox equivalent antioxidant capacity (TEAC).

\section{Estimation of protein carbonyl content:}

The effects of HAPMC extract on oxidative modification of BSA during glycoxidation process were carried out according to method described previously Ardestani and Yazdanparast, 2007 ${ }^{[30]}$. For determination of protein carbonyl content in the samples, $1 \mathrm{ml}$ of $10 \mathrm{mM} \mathrm{2,4-}$ dinitrophenylhydrazine (DNPH) in $2 \mathrm{M} \mathrm{HCl}$ was added to the samples $(1 \mathrm{mg})$. Samples were incubated for $30 \mathrm{~min}$ at RT. Then, $1 \mathrm{ml}$ of cold TCA $(10 \%$, w/v) was added to the mixture and centrifuged at $3000 \mathrm{~g}$ for $10 \mathrm{~min}$. The protein pellet was washed three times with $2 \mathrm{ml}$ of ethanol/ethyl acetate (1:1, v/v) and dissolved in $1 \mathrm{ml}$ of guanidine hydrochloride (6 M, pH 2.3). The absorbance of the sample was read at $370 \mathrm{~nm}$. The carbonyl content was calculated based on the molar extinction coefficient of DNPH. The data were expressed as nmol/mg protein.

\section{In Vitro protein glycoxidation method:}

This assay was adopted from the literature $\mathrm{Wu} \&$ Yen, 2005 and used as an in vitro model for comparing the anti-glycation activities HAPMC ${ }^{[31]}$. In brief, $5 \mathrm{~g}$ BSA and $14.4 \mathrm{~g}$ D-glucose were dissolved in phosphate buffer (1.5 M, pH 7.4) to obtain the control solution with $50 \mathrm{mg} / \mathrm{mL}$ BSA and $0.8 \mathrm{M}$ D-glucose. $2 \mathrm{~mL}$ of the control solution was incubated at $37^{\circ} \mathrm{C}$ for 21 days in the presence or absence of $1 \mathrm{~mL}$ of plant extracts in phosphate buffer (1.5 M, pH 7.4) (the final concentration of plant extract in the $3 \mathrm{~mL}$ test solution was $500 \mathrm{ppm}$ ). The test solution also contained $0.2 \mathrm{~g} / \mathrm{L} \mathrm{NaN}_{3}$ to assure an aseptic condition. After 7 days of incubation, fluorescent intensity (excitation, $330 \mathrm{~nm}$; emission, $410 \mathrm{~nm}$ ) was measured for the test solutions. Percent inhibition of AGE formation by each extract or compound was calculated using the following 
equation, $\%$ inhibition $=[1$ (fluorescence of the solution with inhibitors/Fluorescence of the solution without inhibitors)] $\times 100 \%$.

\section{RESULTS AND DISCUSSION}

The human body defense mechanisms protects the body against free radicals under normal physiological conditions ${ }^{[32]}$. The free radicals were generated in the body during a number of the physiological and biochemical processes, which leads to the production of several radicals. The reactive oxygen species are superoxide radical $\left(\mathrm{O}^{*}\right)$; hydrogen peroxide $\left(\mathrm{H}_{2} \mathrm{O}_{2}\right)$; hydroxyl radical (HO'); peroxyl radical (ROO-) and hypochlorous acid ( $\mathrm{HOCl})^{[33]}$. The reactive nitrogen species (RNS): nitric oxide ( $\mathrm{NO})$ and peroxynitrite $\left(\mathrm{ONOO}^{-}\right)$which are formed by the reaction of $\mathrm{NO}$ and superoxide during inflammatory processes ${ }^{[33]}$. These accumulated reaction products of both oxygen and nitrogen free radical products undergoes protein glycation by nonenzymatic reaction of proteins with glucose and other reducing sugars in living tissues leads to generation of advanced glycation end products (AGEs) ${ }^{[34]}$. These AGEs causes change in molecular pathways that interrupt the pathogenesis of several important diseases including carcinogenesis, cardiovascular diseases, neurodegenerative diseases and also in the process of physiological ageing ${ }^{[35]}$.

Therefore, the present investigation is an attempt to focus the effect of hydroalcoholic pericarp extract of Momordica chochinchinenesis (HAPMC) role on oxidative stress, carbonyl stress and in fructose induced advanced glycation end products.

Antioxidants works as in various pathways by scavenging the radicals and decomposing peroxides by binding to the metal ions and some of them producing synergistic action. These free radicals act by damaging proteins, DNA, and other small molecules. These antioxidants work by three different mechanisms as antioxygen radicals, reducing substances and antiradicals. They work as metal chelators by chain breaking and reducing the chain initiation. Therefore antioxidant activity can be evaluated by different in vitro methods for different mechanisms.

There are a number of assays designed to measure overall antioxidant activity, or reducing potential, as an indication of a host's total capacity to withstand free radical stress ${ }^{\text {[36] }}$. Superoxide anions are thus precursors to active free radicals that have potential for reacting with biological macromolecules and thereby inducing tissue damage ${ }^{[14]}$. In the presence of superoxide dismutase (SOD) as a cellular antioxidant enzyme, which removes this ubiquitous superoxide metabolic product by converting it into hydrogen peroxide and oxygen and this hydrogen peroxide radical readily decomposed into hydroxyl radical in the presence of Catalase 
in biological systems ${ }^{[37]}$. The HAPMC shown to have scavenging property against superoxide, hydroxyl and hydrogen peroxide radicals in a concentration dependent manner as shown in table 1. The HAPMC shown to had reducing Mo (VI) to subsequent formation of a green phosphate/Mo (V) complex at acidic $\mathrm{pH}$ with increasing concentration (Table 1). Nitric oxide is a free radical in terms of its unpaired electron. It reacts with $\mathrm{O}_{2}{ }^{-}$in termination reactions in the mitochondrial matrix, yielding peroxynitrite (ONOO). These oxyradical and peroxynitrite induce oxidative damage to mitochondrial DNA damage and protein inactivation and ATP synthesis ${ }^{[38]}$. The HAPMC had shown better scavenging activity in scavenging nitric oxide free radical as ascorbic acid (Table 1).

DPPH is a stable free radical and accepts an electron or hydrogen radical to become a stable diamagnetic molecule ${ }^{[26]}$. It is an endogenous free radical. The HAPMC can able to reduce the stable radical DPPH to the yellow-colored diphenyl-picrylhydrazine in a dose dependent manner by donating hydrogen atom donating capability thus neutralizing its free radical character (Table 1) ${ }^{[39]}$. Iron, in nature, can be found as either ferrous $\left(\mathrm{Fe}^{2+)}\right.$ or ferric ion $\left(\mathrm{Fe}^{3+}\right)$, with the latter form predominating in foods. This study, the iron reducing power of the HAPMC was estimated from their ability to reduce the $\mathrm{Fe}^{3+}$-ferricyanide complex to the $\mathrm{Fe}^{2+} /$ ferrous form by reducing capability as donating an electron (Table 1) ${ }^{[40]}$. Ferrous chelation may render important antioxidative effects by retarding metal-catalysed oxidation ${ }^{[41]}$. Iron is known as the most important lipid oxidation pro-oxidant among the transition metals due to its high reactive nature. The effective ferrous ion chelators may also afford protection against oxidative damage by removing iron that may otherwise participate in $\mathrm{HO} \cdot$ generating Fenton type reactions as discussed earlier (Table 1). The HAPMC shown to have $\mathrm{Fe}^{2+}$ chelating property in a concentration dependent manner might be due to their hydroxyl radical scavenging property (Graph 1) ${ }^{[42]}$. In this assay, HAPMC interfered with the formation of the ferrous-ferrozine complex, indicating that HAPMC has chelating activity and is able to capture ferrous ion with a higher binding affinity than ferrozine due to its ability to compete with ferrozine for ferrous ion in the solution mixture. In FRAP assay, the capability of test compound that react with ferric tripyridyltriazine $\left(\mathrm{Fe}^{3+}-\mathrm{TPTZ}\right)$ complex and produce a coloured ferrous tripyridyltriazine $\left(\mathrm{Fe}^{2+}{ }_{-}\right.$ TPTZ) ${ }^{[28]}$. In this assay, HAPMC shown to increasing FRAP value in dose dependent effects shown in Graph 2.

In ABTS radical scavenging activity, $\mathrm{ABTS} \bullet+$ radicals involved in the electron-transfer process reactions. This is a direct generation of a stable form of radical to create a blue-green ABTS•+ chromophore prior to the reaction with antioxidants ${ }^{[43]}$. The HAPMC shown to have ABTS•+ 
radical scavenging property might be due to electron donating capability to prevent the formation of stable radical formation (Graph 3).

During the early stage of glycation, Schiff bases are prone to oxidation leads to generating variety of free radicals, reactive carbonyl groups and formation of AGEs. Oxidative modifications of BSA incubated with fructose were demonstrated using a combination of protein carbonyl assay ${ }^{[44]}$. To evaluate HAPMC can reduce the protein glycation and extent of protein carbonyl formation after 21 days by DNPH reagent. As shown in Graph 4, 5 glycation elicited a significant increase of carbonylation of BSA in the presence of fructose compared to the control sample without reducing sugar. However a significant effect on the inhibition of protein oxidation due to glycation was exerted in a dose-dependent manner with increasing the concentrations of HAPMC.

Table1: Effect of Ascorbic acid and HAPMC on $\mathrm{IC}_{50}$ values of different in vitro models.

\begin{tabular}{lll}
\hline Method & Ascorbic acid & HAPMC \\
\hline Superoxide radical & $06.46 \pm 0.31$ & $05.92 \pm 0.29$ \\
Hydroxyl radical & $29.70 \pm 0.21$ & $32.41 \pm 0.84$ \\
Hydrogen peroxide radical & $09.08 \pm 0.29$ & $08.15 \pm 0.19$ \\
DPPH radical & $77.92 \pm 4.23$ & $69.82 \pm 3.91$ \\
Nitric oxide radical & $26.23 \pm 0.19$ & $35.69 \pm 1.41$ \\
Reducing power & $05.41 \pm 0.14$ & $07.44 \pm 0.26$ \\
Phosphomolybdinum method & $04.82 \pm 0.11$ & $05.77 \pm 0.23$ \\
\hline
\end{tabular}

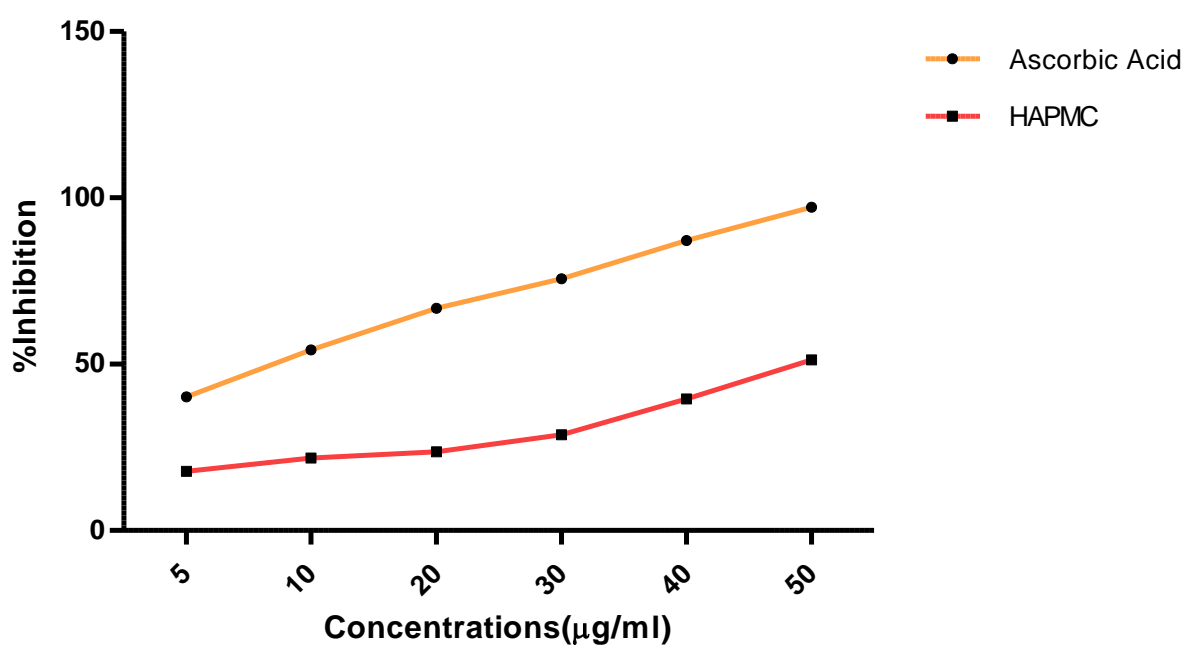

Figure 1: Effect of various concentrations of ascorbic acid and HAPMC on $\mathrm{Fe}^{+2}$ chelating activity. 


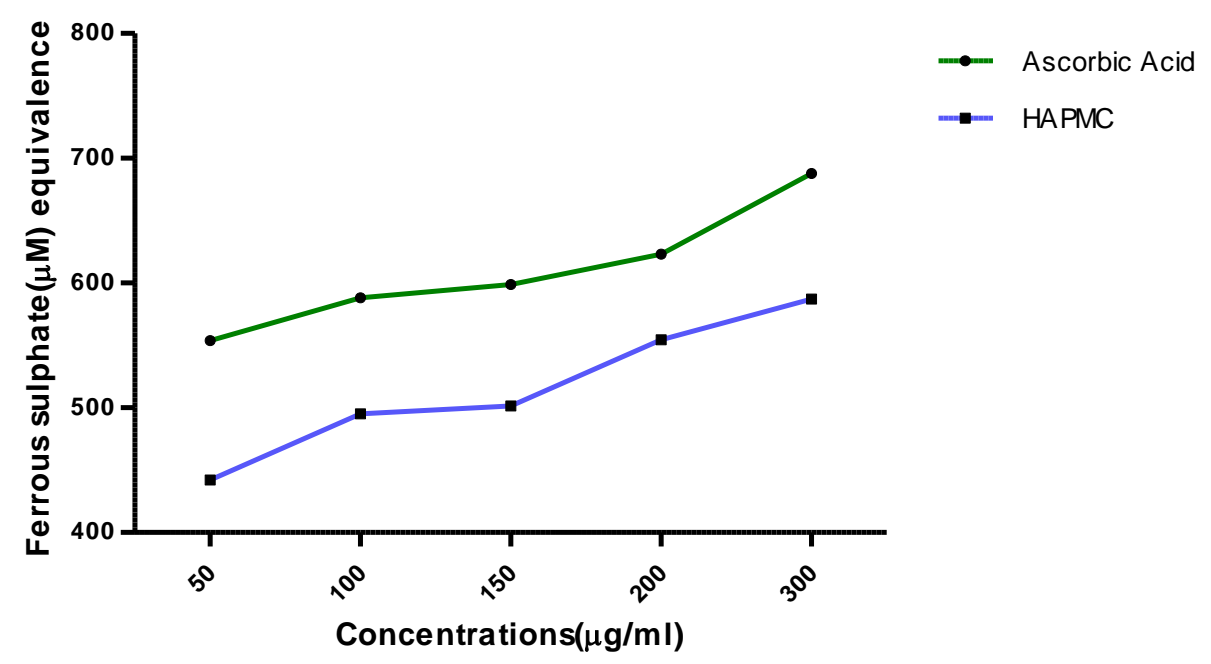

Figure 2: Effect of various concentrations of ascorbic acid and HAPMC on ferric reducing ability power (FRAP).

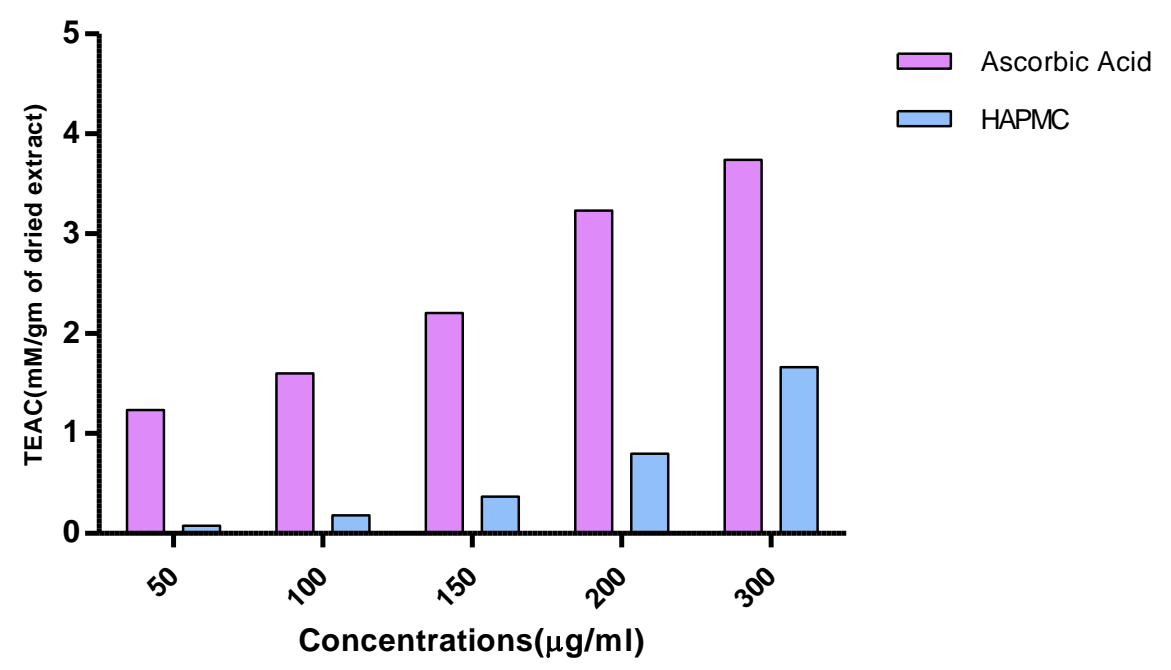

Figure 3: Effect of various concentrations of ascorbic acid and HAPMC on ABTS assay 


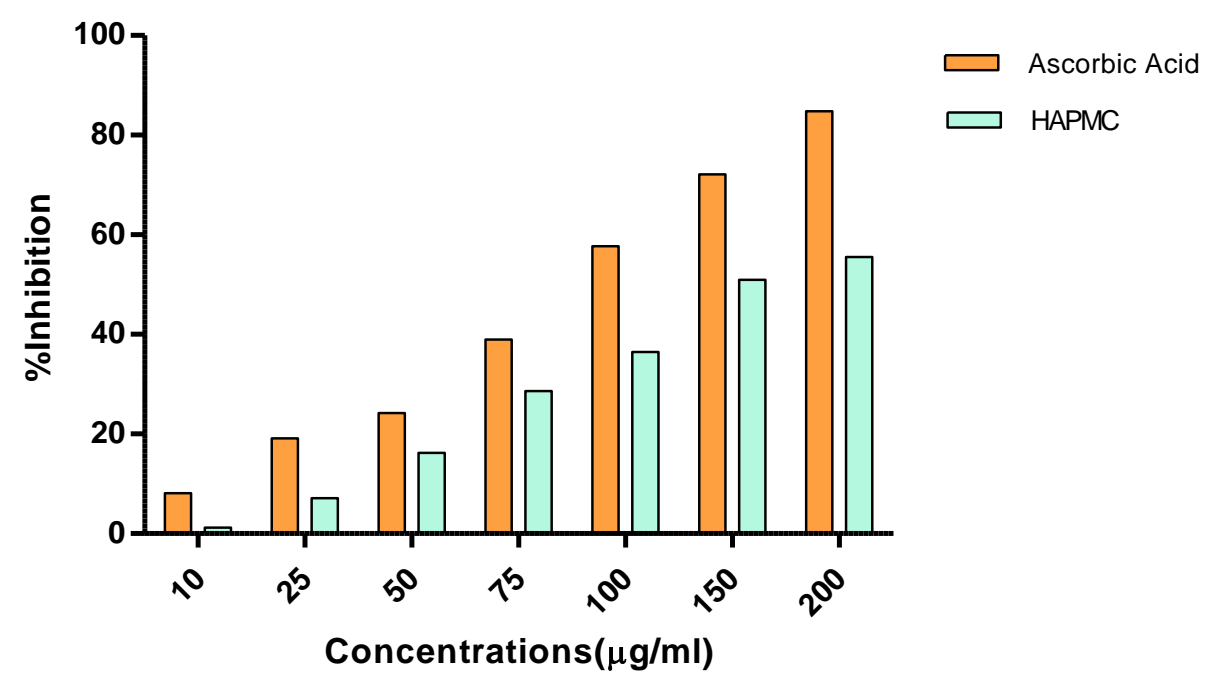

Figure 4: Effect of various concentrations of ascorbic acid and HAPMC on In Vitro glycation of bovine serum albumin

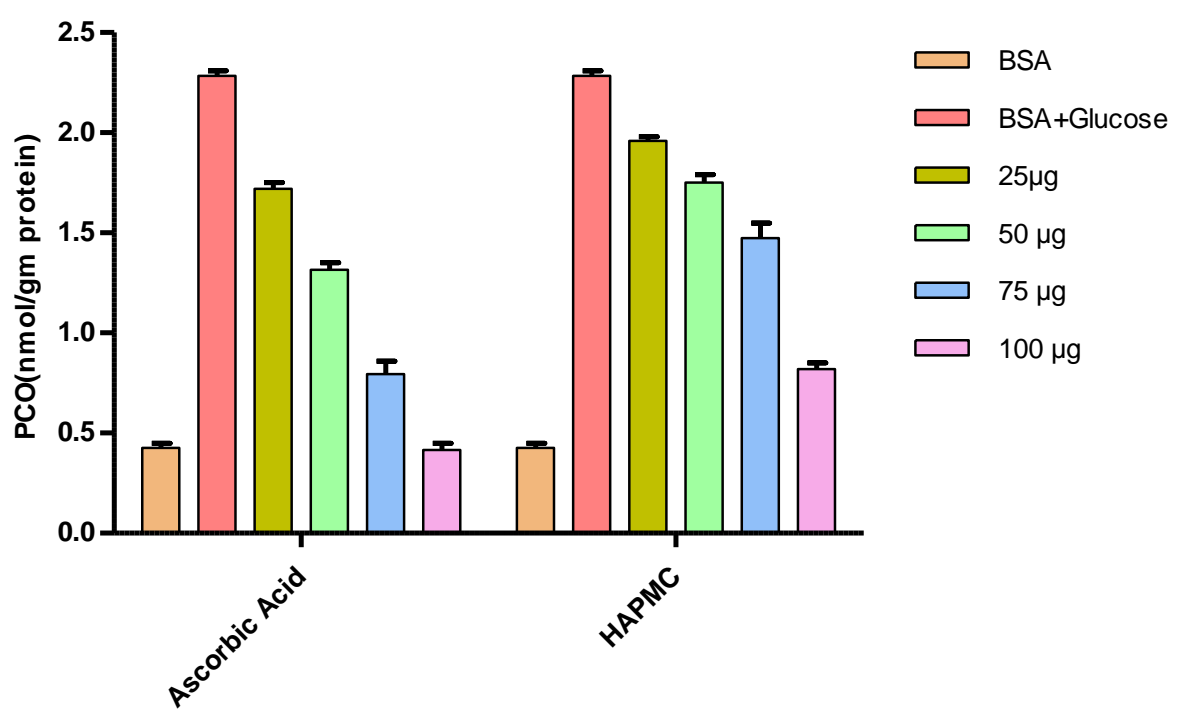

Figure 5: Effect of various concentrations of ascorbic acid and HAPMC on protein carbonyl content (PCO)

\section{CONCLUSION}

It is concluded that, using different in vitro models for estimation the antioxidant potential of Momordica chochinchinenesis showed better effect in scavenging the different free radicals formed during oxidative stress and carbonyl stress. In addition to antioxidant activity it also showed better activity against the formation of protein carbonyl content and protect the structural changes in BSA during glycation processes. 


\section{REFERNCES:}

1 Baynes JW, Thorpe SR. Role of oxidative stress in diabetic complications: a new perspective on an old paradigm. Diabetes. 1999; 48(1):1-9.

2 Nagai R, Mori T, Yamamoto Y, et al: Significance of advanced glycation end products in aging-related disease. Anti-Agine Medicine, 2010;7: 112-119.

3 Ichihashi M, Yagi M, Nomoto K. Glycation stress and photo-aging in skin. AntiAging Medicine,2011;8:23-29.

4 Brownlee M, Biochemistry and Molecular Cell Biology of Diabetic Complications, Nature, 2001, 414 :813-820.

5 Ahmed N, Advanced Glycosylation End Products - Role in Pathology of Diabetic Complications, Diabetes Research and Clinical Practice, 2005; 67(1): 3-21.

6 Thornalley PJ: Use of aminoguanidine (Pimagedine) to prevent the formation of advanced glycation endproducts. Arch Biochem Biophys 2003, 419:31-40.

7 Imai J, Ide N, Nagae S, Moriguchi T, Matsuura H, Itakura Y. Antioxidant and radical scavenging effects of aged garlic extract and its constituents. Planta Med. 1994;60:417-20.

8 Yamaguchi F, Ariga T, Yoshimura Y, Nakazawa H. Antioxidative and antiglycation activity of garcinol from Garcinia indica fruit rind. J Agric Food Chem. 2000;48:1805.

9 Mohammad AE, Mohammad RK, Ali S. Salvia reuterana Extract Prevents Formation of Advanced Glycation End Products: An In Vitro Study. Iranian Journal of Pharmaceutical Sciences Winter 2010: 6(1): 33-50

10 Nakagawa T, Yokozawa T, Terasawa K, Shu S, Juneja LR. Protective activity of green tea against free radical- and glucose-mediated protein damage. J Agric Food Chem. 2002;50:2418-22.

11 Keita M, Yukio F, Naoko Kand Tsuyoshi I. Astragalosides isolated from the root of Astragalus radix inhibit the formation of advanced glycation end products. J. Agric. Food chem. 2009; 57:7666-7672

12 Amin A, Razieh Y. Inhibitory effects of ethyl acetate extract of Teucrium polium on in vitro protein glycoxidation. Food and Chemical Toxicology,2007; 45:2402-2411. 
13 Sirichai A, Thavaree T and Charoonsri C. Mesona Chinensis Benth extract prevents AGE formation and protein oxidation against fructose-induced protein glycation in vitro. BMC Complementary and Alternative Medicine 2014, 14:130

14 Swathi, P., Eswar Kumar, K., 2014. Advanced glycation end products: A review. J.Global Tren.Pharmaceu.Sci.5(2),1729-37.

15 Tsoi AY, Ng TB, Fong Wp, immunomodulatory activity of a chymotrypsin inhibitor of momordica cochinchinensis seeds. J pept Sci, 2006; 12(9): 605-611.

16 Khesorn $\mathrm{N}$ and Patoomratana T.Antimicrobial activity of Hexane and Dicloromethane Extracts from momordica cochinchinensis(lour.) Spreng leves. Thai Pharmaceutical and Health Science Journal, 2009; 4(1):15-20.

17 Jittawan K, Sirthon S. Phytochemical and antioxidant activity of different fruit fraction (pell, pulp, aril and seed) of Thai gac(Momordica cochinchinensis Spreng). Food chemistry, 2011;127:118-1145.

18 Prapaipat K. DNA protective action against h2o2 and uvc of momordica cochinchinensis fruit extrat in human TK6 cells" Thai J. Pharm. Sci. 2012; 36:73-76.

19 Tien PG, Kayama F, Konishi F, Inhibition of tumor growth and angiogenesis by water extract of momordica cochinchinensis fruits. Int jounalof oncology. 2005;26(4):881-889.

20 Beauchamp C and Fridovich I. Superoxide dismutase: improved assays and an assay applicable to acrylamide gels. Anal Biochem. 1971; 44: 276-277.

21 Halliwell B, Gutteridge JMC. In Free radicals, ageing, and disease, free radicals in biology and medicine. Oxford: Clarendron Press.1989; 279-315.

22 Ruch RJ, Cheng SJ, Klaunig JE. Prevention of cytotoxicity and inhibition of intracellular communication by antioxidant catechins isolated from Chinese green tea, Carcinogenesis. 1989;1003-1008.

23 Braca A, Tommasi ND, Bari LD, Pizza C, Politi M, Morelli I. Antioxidant principles from Bauhinia terapotensis. Journal of Natural Products. 2001; 64: 892-895.

24 Ebrahimzadeh MA, Nabavi SF. In vitro antioxidant and free radical scavenging activity of Leonurus cardiaca subsp. Persicus, Grammosciadium platycarpum and Onosma demawendicum, Afr J of Biotech. 2010; 9(51): 8865-8871.

25 Oyaizu M. Studies on product of browning reaction prepared from glucose amine. Japanese Journal of Nutrition. 1986; 44: 307-31. 
26 Prieto P, Pineda M, Aguilar MM. Spectrophotometric quantitation of antioxidant capacity through the formation of a phoshomolybdenum complex: specific application to the determination of vitamin E. Anal. Biochem. 1999; 269: 337-341.

27 Dinis CP, Madeira VMC, Almeida LM. Action of phenolic derivatives (acetaminophen, salicylate, and 5-aminosalicylate) as inhibitors of membrane lipid peroxidation and as peroxyl radical scavengers. Arch Biochem Biophys. 1994; 315: 161-9.

28 Benzie IF, Strains JJ. The ferric reducing ability of plasma (FRAP) as a measure of antioxidant power: The FRAP assay. Anal Biochem. 1996; 239:70-6.

29 Re R Pellegrini N, Proteggente A, Pannala A, Yang M, Rice-Evans C. Antioxidant activity applying an improved ABTS radical cation decolorization assay. Free Radical Biol Med. 1996;26: 1231-7.

30 Ardestani A and Yazdanparast R. Antioxidant and free radical scavenging potential of Achillea santolina extracts. Food. Chem. 2007; 104:21-29.

31 Wu CH, Huang SM, Lin JA, Yen GC: Inhibition of advanced glycation endproduct formation by foodstuffs. Food Func 2011, 2:224-234.

32 Halliwell B and Gutteridge JMC. In Free radicals, ageing, and disease, free radicals in biology and medicine, Oxford: Clarendron Press. 1985; 2:279-315.

33 Sanchez-Moreno C. Review: Methods used to evaluate the free radical scavenging activity in foods and biological systems. Food Sci Technol Int. 2002;8: 121-137.

34 Telci A, Cakatay U, Salman S, Satman I, Sivas A. Oxidative protein damage in early stage type 1 diabetic patients. Diabetes Res. Clin. Pract. 2000;50: 213-223.

35 Swathi P, Eswar Kumar K, Rohini K, Neelakanta Rao N, Absar Q. Inhibitory effects of methanolic pericarp extract of Feronia limonia on in vitro protein glycoxidation. International journal of Pharmacology.2015; 11(1):35-42

36 Wood LG, Gibson PG, Garg ML, A review of the methodology for assessing in vivo antioxidant capacity, J. Sci. Food Agric, 2006;86: 2057-2066.

37 Giorgio M, Trinei M, Migliaccio E, Pelicci PG. Hydrogen peroxide a metabolic byproduct or a common mediator of ageing signals. Nat.Rev.Mol.Cell Bio. 2007; 8(9): $722-8$

38 Wink DA and Mitchell JB. Chemical biology of nitric oxide; Insights into regulatory, cytitoxic, cytoprotective mechanisms of nitric oxide. J.Biol.Chem. 1998; 273: 1104411048. 
39 Pan Y, Wang K, Huang S, Wang H, Mu X, He C. Antioxidant activity of microwaveassisted extract of longan (Dimocarpus longum Lour.) peel. Food Chemistry. 2008; 106: $1264-1270$

40 Haenen GR, Bast A. Protection against lipid peroxidation by a microsomal glutathione-dependent labile factor. FEBS Lett. 1983;159:24-8.

41 Cousins M, Adelberg J, F. Chenb, et al., Antioxidant capacity of fresh and dried rhizomes from four clones of turmeric (Curcuma longa L.) grown in vitro, Ind. Crop. Prod. 2007;25:129-135.

42 Kehrer JP, The Haber-Weiss reaction and mechanisms of toxicity, Toxicology, 2000; 149:43-50.

43 MacDonald-Wicks LK, Wood LG, Garg ML, Methodology for the determination of biological antioxidant capacity in vitro: a review, J.Sci. Food Agric.2006; 86: 20462056.

44 Rosa Martha PG, Sandra L D, Ivan C R, Adriana Maria N G. Anti-glycation Effect of Spices and Chilies Uses in Traditional Mexican Cuisine. Journal of Natural Products, 2010;3: 95-102 